\title{
Mgr Gordana Ljubicic on Translation
}

\author{
Gordana Ljubičić \\ University of Kragujevac, Uzice, Serbia
}

\begin{abstract}
The job of a translator is not an easy one. Very often, when translating from one language to another, the translator is faced with a lot of difficulties. The difficulties arise from the non-parallel structures of different languages, but there are other reasons, too. Although the translator is, in most cases, familiar with the grammar and syntax of the source-language, the problems arise when it comes to words. New words are produced every day in many different ways. Some of these new coinages acquire the status of the regular words of the English vocabulary, but some disappear with the changing of the situation for which they were invented. Very often, these new words are highly imaginative and clever products, but the problem for the translator is how to translate them. Is it possible to find an equivalent in the Serbian language for every newly invented word? Is it possible to translate word for word? And what is the role of a translator in that process?
\end{abstract}

Keywords: translating, translator, new words, foreign language, problems

\section{Introduction}

When translating a written text of any kind from a source-language to his mother tongue, the translator is faced with many difficulties. The main question that he has to consider is how to translate. This may look like nonsense because the job of a translator is to know how to do the translation, but the thing is more serious than it seems to be. The same rules do not apply to the translation of a literary work and the translation of a technical manual, for example. Poetry is more difficult to translate than prose. Many experts think that poetry should not be translated at all, and that the true beauty and the sense of a poem are only discovered when it is read in the language it was written in. In fact, most difficulties arise from the non-parallel structures of different languages. The sentence structures, the use of phrases and idioms differ from language to language, so very often, the translator finds it difficult to be faithful to the original and not lose the artistic value of his translation.

Another point is whether it is possible to do any translation word for word. Of course, many legal texts, like contracts, or scientific and technical texts must be translated this way. But all other written texts belonging to many different genres, allow a certain degree of freedom in translation. Again, the question is how freely a translator can work on the text before it becomes his work and not the original work of the author who wrote it. It seems that the Great Russian poet Yevgeny Yevtushenko was right when he once said that: "Translation is like a woman. If it is beautiful, it is not faithful. If it is faithful, it is most certainly not beautiful."

Of course, the first precondition of successful translation is the knowledge of the language itself; the knowledge of its rules of grammar, syntax, and morphology. We can agree that these are the things that can be learned at school, and that once learned, they remain constant and unchangeable, so every good translator is perfectly skilful at their use. But, when it comes to the knowledge of the vocabulary, the things change. It 
seems that the main difficulty is in words. The languages are like living beings, constantly changing and developing, with the new words emerging every day. Some of the new words manage to overcome all the obstacles and, with the repeated use, stay in the language as a part of its regular corpus, but others disappear very quickly with the changing of the situation for which they were invented. No person can be familiar with all the words of one language. We do not even know all the words of our native language. So, how does a translator cope with this problem of translating the new vocabulary? And how do the ordinary people do that?

To determine the exact number of words in any language, including English, is a difficult and almost impossible task. While some experts claim that the number of words in English has already surpassed one million units, others believe that this number is not greater than three-quarters of a million. The compilers of the Oxford dictionaries rightly believe that it is impossible to count all the words of this language because it is generally difficult to determine what is considered a "word". The questions that the language researchers are facing are numerous. For example, does the same word count as one or two in case when it has the same form but belongs to different word categories (such as "butter", the noun, and "to butter", the verb)? Whether the compound nouns count as one or two words (or sometimes even three) depending on the way they are written (for example, "hot dog", "hot-dog", and "hotdog")? Should the words of the same form but different meaning be counted as one or two (to take "a dish" as an example, with the two different meanings "a bowl" and "a course")? Should all the forms of one word derived by inflectional endings be counted separately or not? Are the abbreviations the real words and is slang something that should be taken into serious consideration when making dictionary entries, especially when we know that such words are rarely long-lasting and that they depend on a specific situation? Another key question is: when we talk about the English language, do we count the words that are not of the English origin but are borrowed from many other different languages? Should the borrowed words be counted as the words of the English language when we know that technical and medical terms are mainly of Latin and Greek origin, and that the culinary terms come from the Italian, Mexican or French cuisine? Do the variants of English that are spoken in other English-speaking parts of the world count as regular English words? All these questions remain without a true and clear answer, and what will be considered a new word is left mainly to time and to the expertise of the language authorities. As Michael Lewis says in his book Implementing the Lexical Approach: "All lexical items are arbitrary-they are simply the consensus of what has been institutionalised, the agreed language which a particular group does use, selected from what they could use, actual language as opposed to theoretically possible language" (1998, p. 24).

The ways of coining new words are numerous. The major word formation processes include derivation, back-formation, conversion, compounding, clipping, reduplication, blending, but also coinage of acronyms, eponyms, abbreviations, nonce words and borrowings from other languages. Although the English language is the lingua franca of today's word, and although it is true that it influences most of other languages, there is also the reverse process in which the words from many other languages invade English and English readily accepts them. We must be aware of what Randolph Quirk said that: "The English language is the text-book example of a language that expands its vocabulary by unashamedly raiding other languages" (Quoted in V. Adams, 1973, An Introduction).

So, when a translator sits in front of a page written in English, he must first read the text in order to decide what words in the text are new to him, and how to find the right translation for the words he does not know. If those new words are the borrowings from other languages, they may not represent the difficulty, because such words are usually adopted in most languages in the same way, unchanged in their form and meaning. Owing to 
the current political, economic and cultural happenings in the world some words impose themselves on all languages and stay rooted in them. That is the case with the word vuvuzela that came into the English language (and the Serbian alike) after the 2010 FIFA World Cup, the tcunami that became world-known after the ecological catastrophe, and the eponym tesla, which is of the Serbian origin, and which denotes the SI unit of magnetic flux density.

Although it is true that the English language is receptive to the words from other languages, the reverse situation is much more common. The English words are flooding the Serbian language (and all the other languages) in such amount that the true and complete translation is often impossible. When we say "true" and "complete", we mean that very often such texts seem to be half-translated, because the same terms appear in both the source-language and the target-language. What are the factors that are responsible for such situation and that interfere with the quality of a translation?

The first of them seems to be the fact that the Serbian language simply does not have the terms for certain English words, especially for those belonging to the fields of IT technologies, fashion or lifestyle in general, so such words cannot be translated at all, or, if they can, their translation would require a lot of space and a lot of words. In this way, the text would become complicated and unattractive to the readers. This is the situation that all the countries in the world are faced with. The words like "gamer", "playback", "download", "trendsetter" and many others cannot be translated word for word, simply because there is not a single corresponding word for them in the Serbian language. So, such words enter the Serbian language in the way in which they appear in English, but with time they adapt themselves to the Serbian morphology and syntax, conform to their rules and became the regular units of the Serbian language.

On the other hand, some English terms have a perfectly corresponding equivalent in the Serbian language, and yet, they are not used in their translated form. The words like "benefit", "office", "cool" or "follow" can be translated using their Serbian equivalents, stylistically correctly and in an acceptable way. Yet, people still use the English words and do not bother about translation. The reasons are manifold. First, the linguistic experts are to blame. There are no strict rules concerning the use of the foreign words in the Serbian language or any professional expertise on what to choose among the many, let alone of how to translate. In Serbia, English is the leading foreign language which is taught in schools from the very first grade, so, one would assume that most people are good speakers of it, but, unfortunately, that is not the case. However, ignorance does not stop the people from showing off with their "knowledge" of English and from trying to insert an English word wherever they think is right, very often in a wrong concept or using the incorrect pronunciation. By doing that, they make changes in the English language, and those changes sometimes become so influential that they become widely accepted. Very often, such words go through a semantic shift and change their meaning when used in the Serbian language. The translator must be aware of that fact when working on a translation. To give an example, the English word "juice" is now, in the Serbian language used only for the orange juice and not for the whole category of that beverage in general. The word "instructor" is only understood in the American sense of the word as "someone teaching a skill such as driving or skiing", and never in the sense of a school or university teacher. Sometimes, funny translations can be seen in leaflets or magazines advertising certain products. For example, a butcher shop is advertising one of its products using a pleonasm "a hot-dog viršla" where "viršla" is the Serbian equivalent for a "hot-dog": the reason for this may be to make it clear that the product in question is not made of chicken meat. 
We must also mention the so-called "false friends", the words that are easily confused, because they look like Serbian words but have a completely different meaning. For example, when we talk about the school terminology, there are considerable differences in English and Serbian. In Serbian, the word "professor" can be used to describe anyone who is teaching in the upper classes of primary and secondary school, while in English it applies only to some of the University teachers. The English word "student" in Serbian describes only the people studying for the university degree, while in the United States of America it can be applied to any pupil at any level of education, as it is derived from the verb "to study". Also, the English word "course" in Serbian translation refers only to the type of training for some practical skill which is performed outside the formal system of education (like a language course, a driving course, etc.), and not to the subjects studied at the University. A further confusion is caused when talking about "higher education". In Serbian language it is "visoko obrazovanje" ("high education"), which is easily confused with the secondary education in the USA ("high school"). When talking about the school system in the English-speaking world, the translator must be aware that "a public school" must, by no means be translated in Serbian as "javna škola" which is a term that has a negative connotation in our language.

The mistakes like these almost certainly occur due to the incompetence of the people who are doing the translation. But sometimes, other reasons must be taken into consideration. In the world of today the things are happening fast and any delay in placing the information immediately, is unacceptable. The right timing demands quick translation and people whose job is to follow the news on the world webs or in foreign magazines do not have time to think about stylistics or to ponder endlessly on the best and most appropriate word in Serbian to use. It is much easier to use the English word and to incorporate it into the article translated for the Serbian readers. In doing this, the attractiveness and correctness of the whole translation is often lost. But if the readers do not mind, and if they understand the words without translation they will use it on a daily basis and with time will become part of the Serbian language, first in the informal communication and later, maybe in the official use.

Another reason why some words are not translated at all, are the social groups that use the same jargon connected to their profession, trade or age. Their discourse is often full of foreign words because they find it easier to use the English words, than to look for a translation in their mother tongue; the process which can be a waste of time and effort for them. Such groups perfectly understand each other because they share the same register and their communication is flawless, even without every word being translated. Especially interesting is the discourse of the young people. They, owing to their (true) knowledge of English, often speak a variant of Serbglish, that is, a mixture of Serbian and English with no need for translation, so that, very often, their conversation becomes incomprehensible to other people who do not belong to their age group. Again, young people modify the English language, because after some time they adapt the English words to Serbian rules: so, for example, the English adjectives "cool" and "fancy" acquire the Serbian forms of comparison and are compared like "kul-kuliji-najkuliji" or "fensi-fensiji-najfensiji".

The fact is that the Serbian language shows a kind of inertness when it comes to translating the foreign words. As we said before, there are no agreed rules about the procedures that should be followed when choosing among the foreign words that should enter the official Serbian dictionaries. As our prominent linguist Ivan Klajn says: "Unfortunately, we do not have an appropriate procedure for introducing the new words, everything is chaotic and there is no official procedure." 
The truth also is that the printed dictionaries are slow in the response to language changes. By the time a new word is entered into a printed dictionary, many changes can happen in the oral discourse, and the word can become redundant, or even disappear from the language. Online dictionaries react in a quicker way, but for many new English words and phrases there is no Serbian translation, not even on the Google translator, which is the search engine that most Serbian people use. Yet, there are some exceptions. For example, the term "surfovanje" ("to surf") appeared in the Matica Srpska Dictionary in 2007, while Ivan Klajn and Milan Šipka introduced the words like "attachment", "out", "workshop", "file" and "online" in their Great Dictionary of Foreign Words and Expressions. These authors also claim that, according to some estimations, the words of foreign origin that are assimilated in the Serbian language make up to one quarter of the whole Serbian lexicon.

The English language is fond of making new words, using the processes of compounding and blending, which Serbian language is not. That is why it is sometimes difficult to find the right translation which will satisfy the structures of both languages. For this, we should only look at the lists that some prominent institutions from the English-speaking countries make each year in the field of linguistics. These choices are known as The Word of the Year and are conducted by the Oxford University Dictionaries and Merriam-Webster in Great Britain, and the American Dialect Society and the Global Language Monitor in the USA, to mention only a few. Similar work is done in some other countries of the world, like Germany, Japan, Denmark and Russia, but not in Serbia. A quick look at the last ten-year choice will discover some interesting things.

The Oxford Dictionaries:

\begin{tabular}{|c|c|}
\hline \multicolumn{2}{|l|}{ Year } \\
\hline 2017 & youthquake \\
\hline 2016 & post-truth \\
\hline 2015 & “Face with Tears of Joy” Emoji \\
\hline 2014 & vape \\
\hline 2013 & selfie \\
\hline 2012 & omnishambles (UK), GIF (US) \\
\hline 2011 & squeezd middle \\
\hline 2010 & Big Society (UK), refudiate (US) \\
\hline 2009 & simples (UK), unfriend (US) \\
\hline 2008 & credit crunch (UK), hypermiling (US) \\
\hline 2007 & carboon footprint (UK), locavore (US) \\
\hline \multicolumn{2}{|c|}{ Merriam-Webster: } \\
\hline \multicolumn{2}{|l|}{ Year } \\
\hline 2017 & feminism \\
\hline 2016 & surreal \\
\hline 2015 & $-i s m$ \\
\hline 2014 & culture \\
\hline 2013 & science \\
\hline 2012 & socialism/capitalism \\
\hline 2011 & pragmatic \\
\hline 2010 & austerity \\
\hline 2009 & admonish \\
\hline 2008 & bailout \\
\hline 2007 & $w 00 t$ \\
\hline
\end{tabular}


American Dialect Society:

\begin{tabular}{ll}
\hline Year & \\
\hline 2017 & dumpster fire \\
2016 & fake news \\
2015 & they \\
2014 & \#blacklivesmatter \\
2013 & because \\
2012 & hashtag \\
2011 & occupy \\
2010 & app \\
2009 & tweet \\
2008 & bailout \\
2007 & subprime \\
\hline
\end{tabular}

Global Language Monitor:

\begin{tabular}{ll}
\hline Year & \\
\hline 2017 & truth \\
2016 & Omran Daqneesh in Aleppo \\
2015 & microaggression \\
2014 & the Heart $\vee$ Emoji (for love) \\
2013 & 404 \\
2012 & apocalipse \\
2011 & occupy \\
2010 & spillcam \\
2009 & tweeter \\
2008 & change \\
2007 & hybrid \\
\hline
\end{tabular}

If we do not take into consideration the choices of Merriam Webster which are rather specific and are mainly chosen by the frequency of their appearance in the previous year and not by their newness, the rest three lists contain words that are extremely hard for any translator (and especially any ordinary man) to translate. Some of these words have already become common in the Serbian language and are used on a daily basis. This is the case with "selfie", "tweeter", "tweet", "hashtag", or even "404" (which, in fact, is not a real word). We notice that all these terms are in some way connected with IT terminology, and, as we said before, they are easier to be accepted the way they are, than to be translated. But some other words are almost impossible to translate. The Serbian language does not have, and probably will never have the equivalents for "youthquake", "squeezed middle", "unfriend" and "credit crunch". It is even hard to find the right translation for "post-truth", "dumpster fire", or "spillcam". Of course, the explanations for some of these words and phrases can be found in online dictionaries, but the question is whether and when they will appear in the printed ones. And will any Serbian translations of those words ever appear in any English-Serbian dictionary? Whose job is to translate such entries and to choose the right Serbian word for them? And who is to decide whether the translations are good enough to enter the dictionaries? Will an ordinary Serbian reader, used to printed books, ever have a chance to enjoy some English texts without an effort to learn English, even at the old age?

\section{Conclusion}

There are many questions that are waiting for the answers and many unsolved problems in the area of 
good translating. The issue of word formation is one of the most serious ones. Many of the newly-coined terms are produced every day, and it is hard for anyone not being the native speaker to understand and translate them in an appropriate way. The truth is that many of these new coined terms will disappear from the language faster than the language authorities could decide about their value. A lot of those terms will lose their relevance with the changing of the situation in which they appeared. However, it will not stop the hundreds of brilliant minds to go on inventing new words out of sheer fun and amusement. And a number of translators will be at a loss what to do when faced with some new coinages. Maybe their struggle for pure and correct language use has already been lost. Maybe, in the future, there will be only one language and no need for translation. And maybe, that will not be so bad at all.

\section{References}

Adams, V. (1973). An introduction to modern English word formation. London: Longman.

Bauer, L. (1983). English word-formation. Cambridge: Cambridge University Press.

Oxford English Dictionary. (2011). How Many Words Are There in the English Language?

Kovacevic, Z. (2009). Lazni prijatelji u engleskom jeziku. Beograd: Albatros plus.

Klajn, I., \& Sipka, M. (2012). Veliki recnik stranih reči i izraza. Novi Sad: Prometej.

Lewis, M. (1998). Implementing the lexical approach. Language Teaching Publications.

Ljubicic, G. (2012). Are we really lost in translation? In E. Szoradova (Ed.), Learner-Teacher-Research in Serbian-Slovak Education Environment (pp. 54-61). Slovakia, Nitra: University Constant in the Philosopher.

www.merriam-webster.com/home.htm (Merriam-Webster Online Dictionary)

www.wiki.proz.com/wiki/index.php (Famous Quotes about Translation)

www.prekoramena.com/t.item.170/nove-reci-u-srpskom-jeziku-izguglaj-pa-daunloaduj.html 